Article

\title{
Mechanical and Corrosion Behavior of New Generation Ti-45Nb Porous Alloys Implant Devices
}

\author{
Konda Gokuldoss Prashanth ${ }^{1, *}$, Ksenia Zhuravleva ${ }^{2}$, Ilya Okulov ${ }^{2, \dagger}$, Mariana Calin ${ }^{2}$, \\ Jürgen Eckert ${ }^{1,3}$ and Annett Gebert ${ }^{2}$ \\ 1 Erich Schmid Institute of Materials Science, Austrian Academy of Sciences, Jahnstraße 12, \\ A-8700 Leoben, Austria; juergen.eckert@oeaw.ac.at \\ 2 Leibniz Institute for Solid State and Materials Research (IFW Dresden), Institute for Complex Materials, \\ Postfach 270116, D-01171 Dresden, Germany; kcpochta@gmail.com (K.Z.); okulovilya@yandex.ru (I.O.); \\ m.calin@ifw-dresden.de (M.C.); a.gebert@ifw-dresden.de (A.G.) \\ 3 Department Materials Physics, Montanuniversität Leoben, Jahnstraße 12, A-8700 Leoben, Austria \\ * Correspondence: kgprashanth@gmail.com or Prashanth.kondagokuldoss@oeaw.ac.at; Tel.: +43-3842-804-206 \\ + Present address: Institute of Materials Research, Materials Mechanics, Helmholtz-Zentrum Geesthacht, \\ 21502 Geesthacht, Germany.
}

Academic Editor: Anders E. W. Jarfors

Received: 31 August 2016; Accepted: 26 September 2016; Published: 30 September 2016

\begin{abstract}
Strategies to improve the mechanical compatibility of Ti-based materials for hard tissue implant applications are directed towards significant stiffness reduction by means of the adjustment of suitable $\beta$-phases and porous device architectures. In the present study, the effect of different compaction routes of the gas-atomized $\beta-\mathrm{Ti}-45 \mathrm{Nb}$ powder on the sample architecture, porosity, and on resulting mechanical properties in compression was investigated. Green powder compacted and sintered at $1000{ }^{\circ} \mathrm{C}$ had a porosity varying between $8 \%$ and $12 \%$, strength between 260 and $310 \mathrm{MPa}$, and Young's modulus ranging between 18 and $21 \mathrm{GPa}$. Hot pressing of the powder without or with subsequent sintering resulted in microporosity varying between $1 \%$ and $3 \%$, ultimate strength varying between 635 and $735 \mathrm{MPa}$, and Young's modulus between 55 and $69 \mathrm{GPa}$. Samples produced with $\mathrm{NaCl}$ space-holder by hot-pressing resulted in a macroporosity of $45 \%$ and a high strength of $>200 \mathrm{MPa}$, which is higher than the strength of a human cortical bone. Finally, the corrosion tests were carried out to prove that the presence of residual $\mathrm{NaCl}$ traces will not influence the performance of the porous implant in the human body.
\end{abstract}

Keywords: titanium alloys; sintering; biomaterials; porous materials; corrosion

\section{Introduction}

Ti and its alloys are widely used for biomedical applications due to their suitable mechanical properties, high biocompatibility, and good corrosion resistance [1]. Nevertheless, one of the main goals in the development of next generation of metallic implant materials is to further improve the mechanical compatibility of load-bearing metallic implant devices to human bone. To manufacture replacement material for bone, we need to understand the characteristics and formation of human bone. Human bone is a composite material that is a mixture of both solid and fluid phases, mainly comprised of $\mathrm{Ca}_{10}\left(\mathrm{PO}_{4}\right)_{6}(\mathrm{OH})_{2}$-calcium phosphate (hydroxyl apatite) [2-4]. The combination of hard and stiff apatite combined with collagen give the required strength to the bone by the following mechanism: the soft components in the bone protect the hard components from cracking, and on the other hand the hard components help the soft ones in resisting to yielding under stress. Human bone can be either cancellous or cortical. The cancellous is a spongy version, and the cortical is the compact version of the bone, with the cortical bone roughly four times the mass of the cancellous bone. 
The porosity levels in the cortical bone varies somewhere between $5 \%$ and $30 \%$, whereas the porosity levels in the cancellous bone ranges between $30 \%$ and $90 \%$. However, the porosity levels in the bone are not fixed, and vary depending on several factors, such as loading sequence, ageing process, etc. Hence, a perfect impact material should have stiffness values very close to that of a human bone, and at the same time possess the required strength to fulfil the load-bearing capacity without fracture [2-4]. The Young's modulus of healthy human cortical bone varies between 15 and $30 \mathrm{GPa}$, and that of human cancellous bone is around 0.2-2 GPa [5]. The Young's modulus values of commercial Ti implant materials are much higher; e.g., $\approx 110 \mathrm{GPa}$ for cp-Ti, $112 \mathrm{GPa}$ for $(\alpha+\beta)$-type Ti-6Al-4V. Such a large mismatch in the values of the Young's modulus can cause stress shielding and degradation of the bone surrounding the implant [6]. Therefore, metastable $\beta$-type Ti-Nb alloys are the current focus of many research activities, as at 40-45 wt \% Nb, they show Young's modulus values of 60-62 GPa after quenching from the $\beta$-phase region [7]. However, those values are still too high compared to those of human bone. Another strategy to reducing the stiffness of a metallic body is the introduction of porosity. Oh et al. [8] demonstrated that by sintering gas-atomized Ti particles, samples with porosities up to $36 \%$ (microporosity) can be obtained, where the micropores are formed as open spaces between the partially-sintered powder particles. With increasing porosity up to $36 \%$, the Young's modulus was reduced to $20 \mathrm{GPa}$. However, at the same time, those porous samples exhibited a significant decrease of strength. The strength of metallurgically-processed powder samples depends sensitively on the level of interlinking and interconnection of the metallic particles. This is determined by the composition-dependent properties of the material (e.g. ductility), thermal properties (flowability), and processing parameters (e.g., applied temperature and sintering time). In the previous works of the authors, it has been demonstrated that hot-pressed powder samples have a significantly higher strength than samples produced by other methods, such as sintering $[9,10]$. Therefore, hot-pressing is expected to yield a better interconnection of metallic particles [11] than sintering without pressure and to increase the strength of porous bodies.

It has been demonstrated in our previous studies that the increase of porosity reduces the Young's modulus to the desired values, but the strength of the samples becomes very low. For example, $\beta-\mathrm{Ti}-40 \mathrm{Nb}$ alloy samples produced by green compaction, sintering at $1000^{\circ} \mathrm{C}$, and water quenching with a porosity range of $36 \%-80 \%$ had Young's modulus values from 1.5 to $3 \mathrm{GPa}$ and strength values from 10 to $35 \mathrm{MPa}$ [12]. The same tendency was observed in works of different authors. Niu et al. [13] used carbamide particles as space-holders, and the final porosity was $55 \%-75 \%$. The samples were produced by loose sintering, the Young's modulus of these samples was 3-6.4 GPa, and the plateau stress varied between 10 and $35 \mathrm{MPa}$ [13], which is too low for load-bearing applications, since a typical human bone exhibits a compressive strength ranging between 150 and $300 \mathrm{MPa}$ [14]. In the present work, it will be demonstrated that even samples with high porosity have a high strength when they are produced by hot-pressing instead of sintering.

From the literature, it is known that the strength of porous samples can be calculated from the known characteristics of a non-porous sample of the same material. The principle equation is the following:

$$
\sigma_{p l}=C \sigma_{d}\left(\frac{\rho_{f}}{\rho_{d}}\right)^{n}
$$

where $\sigma_{p l}$ is the plateau stress of a porous sample, $\rho_{f}$ and $\rho_{d}$ are densities of a porous and a "bulk" material, and $\sigma_{d}$ is the strength of a bulk sample. $C$ and $n$ are coefficients which depend on the processing method and parameters [15-18]. Equation (1) may be used to estimate the compressive strength of the porous samples, provided the compressive strengths of the bulk samples are known, with the assumption that the bulk sample has a 100\% theoretical density. Powder metallurgy offers a variety of methods for the production of macroporous samples. One of the most commonly used methods is the space-holder technique, which allows the precise control of macroporosity by controlling the pore shape and size of the space-holders [12,19]. From the previously published studies of different authors, the most commonly used space-holder materials are the following: 
ammonium hydrogen carbonate [20], carbamide (urea) [21], $\mathrm{NaCl}$ [15], raw cane sugar [22], $\mathrm{Mg}$ [17], and $\mathrm{Cu}$ [23]. The applicability of the different space-holder materials depends on the processing parameters (pressure, temperature, and so on) which will be used during the compaction process.

$\mathrm{Mg}$ has a boiling point at $1107^{\circ} \mathrm{C}$, and in most cases is removed from the sample during sintering at $\approx 1200{ }^{\circ} \mathrm{C}$ [24]. Additionally, its vapor can contaminate the sintering atmosphere and the equipment. The important benefits of using $\mathrm{Mg}$ as space-holder are: (i) it can perform as an oxygen getter for Ti alloys [25]; and (ii) it is a so-called "vital" (non-toxic) element [26]. Cu has a relatively high melting point of $1084.6{ }^{\circ} \mathrm{C}$ and a boiling point of $2562{ }^{\circ} \mathrm{C}$, but the expressed cytotoxic and inflammatory effects of $\mathrm{Cu}$ and $\mathrm{Cu}$-containing alloys on the human body [27] limit its biomedical applications. $\mathrm{Al}$ has a melting point of $660.3^{\circ} \mathrm{C}$ and a boiling point of $2470{ }^{\circ} \mathrm{C}$, and is known to be toxic to the human body [28]. Another group of space-holder materials are organic materials such as poly methyl-methacrylate (PMMA), polymers, $\mathrm{NH}_{4} \mathrm{HCO}_{3}$, and so on. The heat treatment decomposition reaction of $\mathrm{NH}_{4} \mathrm{HCO}_{3}$ follows as $\mathrm{NH}_{4} \mathrm{HCO}_{3} \rightarrow \mathrm{NH}_{3} \uparrow+\mathrm{H}_{2} \mathrm{O} \uparrow+\mathrm{CO}_{2} \uparrow$ and leads to the formation of $\mathrm{N}$ and $\mathrm{O}$, which contaminate the Ti matrix at elevated temperatures [29] and release $\mathrm{NH}_{3}$, which is harmful to the human body $[22,30]$.

$\mathrm{NaCl}$ is used as a space-holder and has melting and boiling points of $801{ }^{\circ} \mathrm{C}$ and $1413{ }^{\circ} \mathrm{C}$, respectively; hence, it can withstand high sintering temperatures (used in the present study) without evaporation or decomposition, which are typically the problems of other space-holder materials. Due to a reasonably high mechanical strength, $\mathrm{NaCl}$ particles are also expected to be suitable for a hot-pressing procedure [19], unlike the other space-holder materials. Nevertheless, a major concern about the application of $\mathrm{NaCl}$ as a space-holder material is a risk that residual $\mathrm{NaCl}$ particles (when the $\mathrm{NaCl}$ particles are present isolated in the matrix and do not get in contact with water) can cause corrosion of the metal matrix because of the incomplete dissolution in some pores. Additionally, the situation after implantation can make this aspect even more severe, since conditions of crevices or occluded cells (pores) are generated which can be related to chloride ion accumulation and $\mathrm{pH}$ value drop. We report on the effect of different compaction routes-i.e., sintering at $1000{ }^{\circ} \mathrm{C}$ and quenching, or hot-pressing at $600{ }^{\circ} \mathrm{C}$ at different pressures with a slow cooling, or the combination of both. Consequences for the mechanical performance of the porous alloy bodies are discussed with a view to the selection of the most suitable approach for maximum strength increase.

The mechanical tests were carried out in the samples produced without the use of space-holder to analyze only the microporosity change and its consequences. Samples with space-holders are produced only to address the question of corrosion stability, where electrochemical corrosion studies of porous alloy samples in Ringer solution with maximum $\mathrm{NaCl}$ concentration (saturated solution) and/or significant $\mathrm{pH}$ value change from 7.4 to $\mathrm{pH} 0.5$ were conducted.

\section{Experimental Section}

For the present study, gas-atomized Ti-45Nb powder was employed as prepared by TLS Technik, Bitterfeld, Germany. The particles had a spherical shape and a particle size of $>100 \mu \mathrm{m}$. The oxygen content of the alloy powder was analyzed by hot gas extraction method. A typical value of $0.2 \mathrm{wt} \%$ was obtained. A first set of samples was green compacted with 40 and $50 \mathrm{kN}$ at room temperature for $30 \mathrm{~min}$ in vacuum. Further, these samples were encapsulated in a quartz ampulla and sintered at $1000{ }^{\circ} \mathrm{C}$ for $4 \mathrm{~h}$ in argon and water quenched. Water quenching was carried out after the samples were taken out by breaking the quartz ampulla. A second set of powder samples was hot-pressed at $600{ }^{\circ} \mathrm{C}$ with 25 and $50 \mathrm{kN}$ for $30 \mathrm{~min}$ in vacuum and slowly cooled down inside of the hot-press chamber. A third set of samples was hot-pressed at $600{ }^{\circ} \mathrm{C}$ with 25 and $50 \mathrm{kN}$ for $30 \mathrm{~min}$ in vacuum, cooled down inside of the hot-press chamber, and then additionally sintered at $1000{ }^{\circ} \mathrm{C}$ for $4 \mathrm{~h}$ in argon (encapsulated in a quartz ampulla) and water quenched (after the samples were taken out by breaking the quartz ampulla). Macroporous samples were produced using $\mathrm{NaCl}$ particles of $125-300 \mu \mathrm{m}$ size as space-holder material. Ti-45Nb powder sample was mixed with $\mathrm{NaCl}$ ( $\sim 2: 1$ ratio) and hot pressed at $600{ }^{\circ} \mathrm{C}$ for $30 \mathrm{~min}$ in vacuum. The space-holder was then removed by immersion 
in water $\left(80^{\circ} \mathrm{C}\right)$ for $6 \mathrm{~h}$. The phase composition of the samples was analyzed using a Bruker X-ray diffractometer (XRD) (Bruker DALTONIK GmbH, Bremen, Germany) with Co-K $\alpha$ radiation equipped with a monochromator. The microstructure and morphology of compacted and fractured samples was characterized with a Jeol 6400 scanning electron microscope (SEM) (Jeol, München, Germany). To determine the mechanical properties, compression tests were carried out at room temperature using an Instron 5869 device (INSTRON, Darmstadt, Germany) with a strain rate of $10^{-3} \mathrm{~s}^{-1}$. The samples used for the compression tests were cut to have a diameter of $3 \mathrm{~mm}$ and height of $6 \mathrm{~mm}$, and cleaned with ethanol to remove any surface contaminations. Their density was measured prior to testing by the Archimedes method. The porosity of highly porous samples was determined by geometrical method; i.e., dividing their mass by measured volume. For corrosion analysis, hot pressed Ti- $45 \mathrm{Nb}$ samples were electrically connected and embedded in epoxy resin. The cross-sectional areas of the cylindrical samples with $3 \mathrm{~mm}$ diameter were mechanically ground up to $\mathrm{SiC}$ grit 4000 , cleaned with water and ethanol, and used as working electrodes in electrochemical testing. Anodic potentiodynamic polarization measurements were conducted at $37 \pm 0.1^{\circ} \mathrm{C}$ in Ringer's solution $(8 \mathrm{~g} / \mathrm{L} \mathrm{NaCl}, 0.2 \mathrm{~g} / \mathrm{L}$ $\mathrm{KCl}, 0.2 \mathrm{~g} / \mathrm{L} \mathrm{CaCl}_{2}$, and $1 \mathrm{~g} / \mathrm{L} \mathrm{NaHCO}_{3}$ ) with $\mathrm{pH}=7.5$. For simulation of extreme environmental conditions, this standard Ringer solution was further (i) saturated with $\mathrm{NaCl}$ by addition of $280 \mathrm{~g} / \mathrm{L}$ salt; (ii) $\mathrm{pH}$-adjusted with $\mathrm{HCl}$ to $\mathrm{pH} 0.5$; and (iii) a combination of both $\mathrm{NaCl}$ saturation and adjustment to $\mathrm{pH} 0.5$ was realized. A Solarton SI Electrochemical Interface connected to a tempered three-electrode-cell with a Pt net as counter electrode was used, with a saturated calomel reference electrode (SCE with Standard Hydrogen Electrode potential $\mathrm{E}_{\mathrm{SHE}}=0.241 \mathrm{~V}$ at $25^{\circ} \mathrm{C}$ ) and the embedded alloy sample as working electrode. Before the actual polarization measurements, the samples were kept at open circuit potential (OCP) conditions for $1 \mathrm{~h}$; meanwhile, the potential was monitored. The linear dynamic polarization was started at $-0.2 \mathrm{~V} v$ s. OCP, and was increased at a constant rate of $0.5 \mathrm{mV} / \mathrm{s}$ up to a value of $2 \mathrm{~V}$ vs. SCE. Each test was performed two times to verify the reproducibility of the results. From the representative polarization curves, the characteristic corrosion parameters were estimated by graphical extrapolations.

\section{Results and Discussion}

Three types of compacted samples with different microporosities (and thus, different densities) were produced without space-holder for this study, according to the description in the experimental section. For these samples, the porosity was measured in air and in water by Archimedes' method. Samples produced by green compaction (with different pressures from 40 to $50 \mathrm{kN}$ ) and sintered at $1000{ }^{\circ} \mathrm{C}$ had porosity values of $12 \% \pm 2.5 \%$ (40 kN load) and $8 \% \pm 2 \%$ (50 kN load), and the higher the green compaction pressure was, the lower was the porosity. Samples produced by hot-pressing at $600{ }^{\circ} \mathrm{C}$ with different pressures $(25$ and $50 \mathrm{kN}$ ) had porosity values of $3 \% \pm 0.5 \%$ and $2 \% \pm 0.5 \%$, respectively, and these values did not change much with changing pressure. Samples produced by hot-pressing and sintering had porosity values of $1.5 \% \pm 0.2 \%$ (for $25 \mathrm{kN}$ load) and $1 \% \pm 0.2 \%$ (50 kN load). The density values of hot-pressed and hot-pressed plus sintered powder compacts were close to the theoretical density of the Ti- $45 \mathrm{Nb}$ alloy of $5.7 \mathrm{~g} / \mathrm{cm}^{3}$ [31]. The porosity of samples made by hot-pressing followed by sintering is only somewhat lower than that of hot-pressed samples. A similar effect was previously described in the literature for NiTi alloy bodies produced by sintering with space-holders [19]. The micropores in compacted powder samples usually originate from the packing of the metallic powder particles (gaps between spherical powder particles) or from gas inclusions [32].

SEM images of the green compacted and sintered Ti- $45 \mathrm{Nb}$ alloy sample are shown in Figure 1a, clearly showing the presence of spherically-shaped powder particles. Every single powder particle is clearly detectable, and is connected with its neighbor particles by small necks (indicated by arrows). The formation of a neck between powder particles is a necessary condition of sintering. It determines the strength of the sintered body: the stronger the neck, the higher the strength of the porous body [33]. In Figure 1a, the neighbor particles have only small contact areas, which is typical for green compacted samples. This implies that sintering at $1000^{\circ} \mathrm{C}$ (without pressure) followed by water quenching is not 
very effective for enhancement of the interconnection of the Ti- $45 \mathrm{Nb}$ particles. In contrast, samples produced by hot-pressing and by hot-pressing followed by sintering do not have visible pores, as is obvious from the SEM images in Figure 1b,c, respectively. The reason for this is a much stronger connection between the powder particles which occurs upon a so-called "pressure assisted sintering", where the driving forces of the sintering are both the pressure and the surface energy [34]. The necks between the powder particles are stronger, and the contact area is larger than in the previous green compacted and sintered case. The pressure applied upon elevated temperature during hot-pressing causes plastic yielding of the contact areas between particles and expansion of the contact points into contact areas, thus making the connection stronger and the porosity lower [35]. Therefore, the density of the samples is higher (i.e., $\approx 5.6 \mathrm{~g} / \mathrm{cm}^{3}$ ).
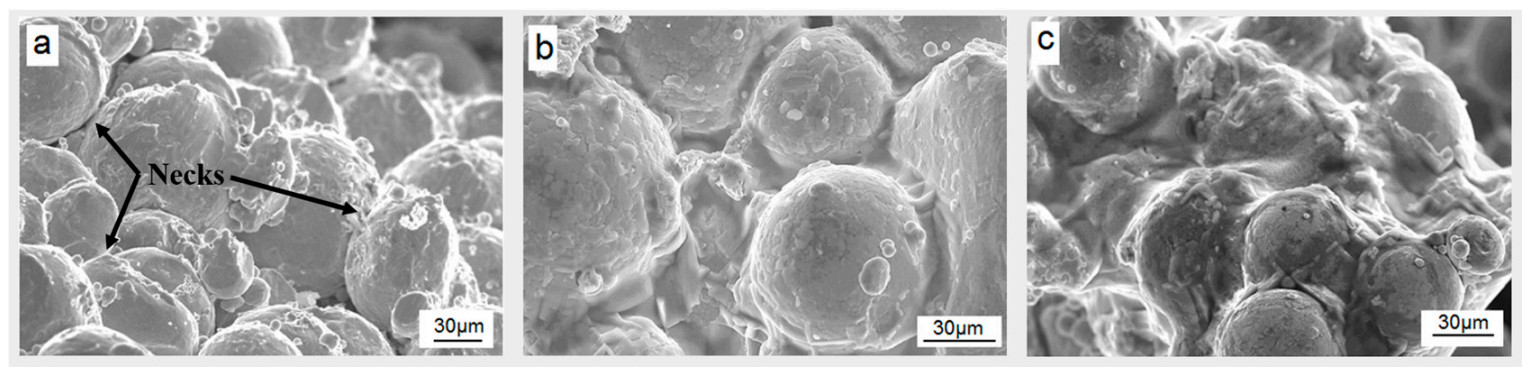

Figure 1. Typical SEM images of samples after (a) green compaction $(50 \mathrm{kN})$ and sintering at $1000{ }^{\circ} \mathrm{C}$ followed by water quenching; (b) hot-pressing at $600{ }^{\circ} \mathrm{C}$ with $50 \mathrm{kN}$; and (c) hot-pressing at $600{ }^{\circ} \mathrm{C}$ with $50 \mathrm{kN}$ followed by sintering at $1000{ }^{\circ} \mathrm{C}$ and water quenching.

The phase composition of Ti-Nb alloys has a strong influence on their mechanical properties. For low values of the Young's modulus (which are desired for biomedical applications), the presence of single $\beta$-phase is expected because it has the lowest modulus among all the phases in this alloy system [7]. The starting gas-atomized Ti-45Nb powder has only the reflection of a $\beta$-type phase on the XRD pattern, as demonstrated in Figure 2a. After different heat treatment routes and cooling rates, the phase composition of the initial alloy can be changed. The pattern of a gas-atomized powder that was green compacted and sintered at $1000{ }^{\circ} \mathrm{C}$ is shown in Figure $2 \mathrm{~b}$. The narrow peaks suggest that the lattice strain is relatively low and that the mean grain size is large on the microscale. The peaks of $\beta-(\mathrm{Ti}, \mathrm{Nb})$ phase are clearly visible in the pattern and no distinct predominant peaks of other phases are observed. This is also valid for Ti-45Nb powder hot-pressed at $600{ }^{\circ} \mathrm{C}$ (Figure $2 \mathrm{c}$ ) as well as for hot-pressed and sintered powder (Figure 2d). This suggests that neither sintering at $1000{ }^{\circ} \mathrm{C}$ and water quenching, nor hot-pressing at $600{ }^{\circ} \mathrm{C}$ and slow cooling, nor a combination of both causes the stabilization of any other phase. To sum up, according to the XRD patterns, a single $\beta$-type phase is present in gas-atomized Ti-45Nb powder after compaction by all three routes, no matter what temperature and cooling rate was used. However, the phase resolution of the XRD is limited. Our previous study with TEM revealed that one can expect a certain minor fraction of $\omega$-phase in slowly cooled samples after hot-pressing [11,36,37]. In general, the presence of the $\omega$ phase has a strong influence on the mechanical behavior of a Ti alloy, and is not desired in biomedical alloys because of its relatively high Young's modulus value [38]. 


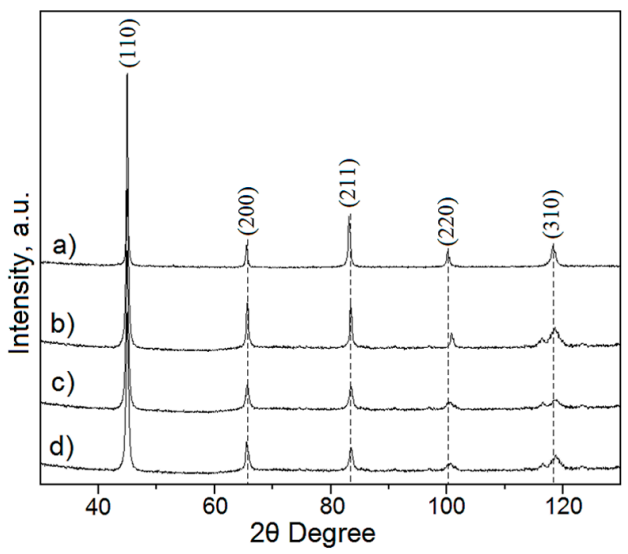

Figure 2. XRD patterns of (a) gas-atomized Ti- $45 \mathrm{Nb}$ powder; and Ti- $45 \mathrm{Nb}$ samples produced by (b) green compaction $(50 \mathrm{kN})$ and sintering at $1000{ }^{\circ} \mathrm{C}$ followed by water quenching; (c) hot-pressing at $600{ }^{\circ} \mathrm{C}$ with $50 \mathrm{kN}$; and (d) hot-pressing at $600{ }^{\circ} \mathrm{C}$ with $50 \mathrm{kN}$ followed by sintering at $1000{ }^{\circ} \mathrm{C}$ and water quenching, where only peaks corresponding to the $\beta$ phase are observed.

In the compression test curves in Figure 3, the different stress and strain values of the different sample types can be recognized. All three curves have clear areas of elastic and plastic regimes. The elastic regime in all curves is represented by the linear part of the curve in the beginning of the experiment, and after a certain load, the elastic deformation turns to plastic. The curve of the green compacted and sintered sample is dramatically different from the other two curves, and has significantly lower strength and strain values. It is suggested that the deformation mechanisms of green compacted and sintered samples and the other two types of samples are totally different. The samples produced by hot-pressing as well as by hot-pressing followed by sintering have a low microporosity and a high density which is close to the theoretical density of the alloy. These samples are deformed like bulk cast samples, as described in a work by Calin et al. [39], where the stress-strain curves demonstrated a remarkable strain hardening, but do not show the double yielding effect originating from a stress-induced $\alpha^{\prime \prime}$-martensite formation. This can be also attributed to the samples produced by hot-pressing as well as hot-pressing followed by sintering. The green compacted and sintered samples have higher porosity, and their high strain can be a result of the pore closing during the compression tests. The applied pressure causes deformation of the pore walls, forcing the pores to close, and then the formed "non-porous" system is submitted to compression as a bulk body [40]. The high strain may also be due to early breaking of unstable necks, thereby leading to increased apparent density or both closure of pores and breaking of necks.

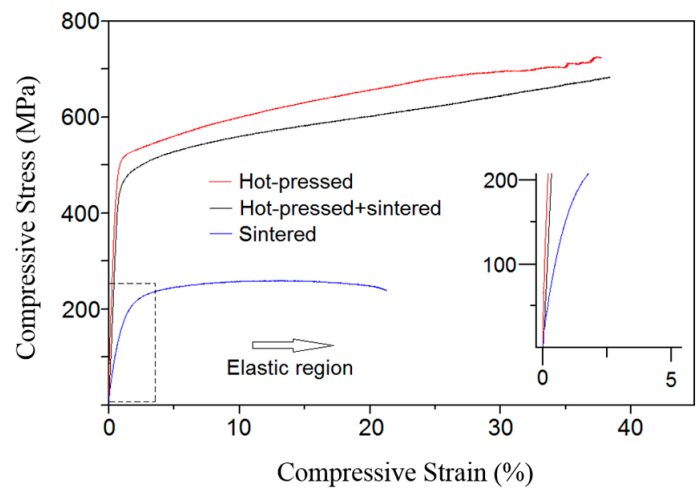

Figure 3. Typical stress-strain curves of samples produced by green compaction $(50 \mathrm{kN})$ and sintering at $1000{ }^{\circ} \mathrm{C}$ followed by water quenching, hot-pressing at $600{ }^{\circ} \mathrm{C}$ with $50 \mathrm{kN}$ and by hot-pressing at $600{ }^{\circ} \mathrm{C}$ with $50 \mathrm{kN}$ followed by sintering at $1000{ }^{\circ} \mathrm{C}$ and water quenching, obtained by compression tests. 
The Young's modulus (from data in the inset of Figure 3) was calculated from the linear part of the stress-strain curve in the elastic region according to the equation $\mathrm{E}=(\sigma / \varepsilon)=\left(\mathrm{F} \cdot \mathrm{L}_{0}\right) /\left(\mathrm{A}_{0} \cdot \Delta \mathrm{L}\right)[41]$, where $\sigma$ and $\varepsilon$ are stress and strain, respectively (can be taken from the curve), $\mathrm{F}$ is a compression force, and $A_{0}$ and $L_{0}$ are initial cross sectional area of the sample and its initial length, respectively. $\Delta \mathrm{L}$ is the length change of the sample during compression. $\mathrm{F}$ and $\Delta \mathrm{L}$ are also among the output raw data calculated by the device during the compression test. The Young's modulus of the green compacted and sintered sample is obviously lower than that of the other samples, which can be explained by relatively high porosity of the alloy. The mechanical data collected from the compression tests for samples produced by three different ways is summed up in Figure 4. Samples produced by green compaction followed by sintering and water quenching had the highest porosity level of $9 \% \pm 4.5 \%$ and the lowest ultimate strength level among them. The mechanical properties and porosity of these samples correlated with the applied pressure during green compaction $(40-50 \mathrm{kN})$, and the strength decreased with increasing porosity. The ultimate strength of these samples with the applied load of $40 \mathrm{kN}$ and $50 \mathrm{kN}$ were estimated to be $261 \pm 3 \mathrm{MPa}$ and $308 \pm 10 \mathrm{MPa}$, respectively. Similarly, the Young's modulus for these samples with the applied loads of $40 \mathrm{kN}$ and $50 \mathrm{kN}$ are observed to be $18.3 \pm 0.4 \mathrm{GPa}$ and $21 \pm 1 \mathrm{GPa}$, respectively. The relatively low strength of these samples is attributed to poor interparticle connection and relatively high porosity. Samples produced by hot-pressing had significantly increased ultimate compression strength, where the samples hot-pressed at a load of $25 \mathrm{kN}$ showed a strength of $635 \pm 12 \mathrm{MPa}$ and the samples hot-pressed at $50 \mathrm{kN}$ showed a strength of $695 \pm 3 \mathrm{MPa}$. The Young's moduli of these samples were observed to be $55 \pm 5 \mathrm{GPa}$ and $69 \pm 1.4 \mathrm{GPa}$, respectively. The value of the Young's modulus is comparable to the one for cast and solution treated bulk alloy samples [33]. The ultimate strength of samples produced by hot-pressing followed by sintering were observed to be $640 \pm 15 \mathrm{MPa}(25 \mathrm{kN}$ load) and $738 \pm 6 \mathrm{MPa}$ (50 kN load); i.e., it was slightly increased compared to hot-pressed only samples. The Young's moduli of these samples were observed to be $54 \pm 4 \mathrm{GPa}(25 \mathrm{kN}$ load) and $63 \pm 1 \mathrm{GPa}(50 \mathrm{kN}$ load), respectively, which is slightly lower than for the samples after hot-pressing. The obtained data trend is in good agreement with that in a study by Bandsiddhi et al. [19], where it was reported that hot-pressing of gas-atomized NiTi powder followed by sintering is beneficial for the strengthening of the alloy samples. The microporosity levels of the hot-pressed samples and samples produced by hot-pressing followed by sintering are nearly similar (i.e., $\approx 2 \%$ ), but there is still a small difference in the values of the Young's modulus. This may be attributed to the different cooling rates that these two types of samples experienced during processing. Only hot-pressed samples were slowly cooled down as last processing step, which may cause the formation of traces of $\omega$ phase, and thus an increase of the Young's modulus [42]. Additional sintering above the $\beta$-transformation temperature and subsequent water quenching can significantly reduce the $\omega$-phase fraction.
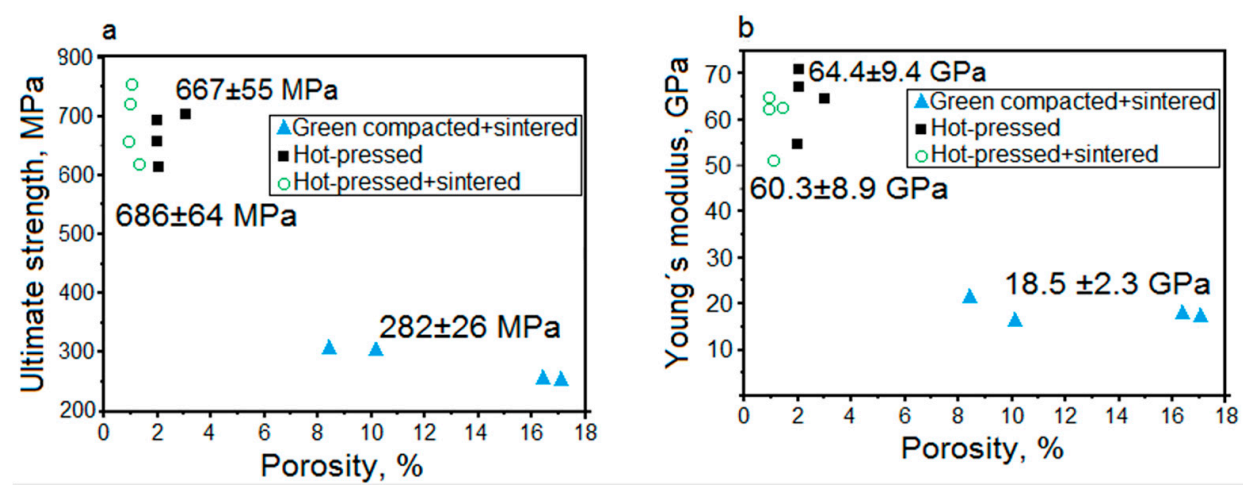

Figure 4. (a) Ultimate strength and (b) Young's modulus of samples produced by green compaction (40 and $50 \mathrm{kN}$ ) and sintering at $1000{ }^{\circ} \mathrm{C}$ followed by water quenching, hot-pressing at $600{ }^{\circ} \mathrm{C}$ with $25-50 \mathrm{kN}$, and by hot-pressing at $600{ }^{\circ} \mathrm{C}$ with $25-50 \mathrm{kN}$ followed by sintering at $1000{ }^{\circ} \mathrm{C}$ and water quenching. 
In Figure 4a, the correlation of the porosity with the strength of the green compacted and sintered samples is linear with a slight decrease, whereas the data for the hot-pressed as well as hot-pressed and sintered samples is focused in one small area. The green compaction followed by sintering leads to the formation of different porosities in the samples, and the higher the green compaction pressure was, the lower was the porosity. The strength is dependent on the porosity, and therefore decreased from 308 to $256 \mathrm{MPa}$ with increasing porosity from $4.5 \%$ to $13.5 \%$. The hot-pressed as well as hot-pressed and sintered samples have almost constant porosity, no matter which pressure was applied during the hot-pressing step, and the distribution of the strength data can be attributed to the presence of experimental errors. In Figure $4 \mathrm{~b}$, the correlation between the porosity and Young's modulus values is linear for the green compacted and sintered samples. This can be explained by difficulties in the preparation of the compression test samples with high porosity: the manufacturing of perfect coplanar surfaces of the top and bottom of the sample is impossible because of the porous inner architecture of the alloy. Therefore, the values of the Young's modulus in the present paper are only given for the reference, and the main focus falls on the strength values, which are not so sensitive to the coplanar surfaces of the sample. The Young's modulus data for the hot-pressed as well as hot-pressed and sintered samples has some dispersion, even though the porosity of the samples is roughly the same. The reason for that is a difference in the phase composition between the samples which were slowly cooled in the hot-press chamber and those which were quenched. It can be argued that the samples produced by hot-pressing followed by sintering have lower Young's modulus than only hot-pressed samples, because they are expected to have lower or no content of $\omega$ phase (a reasonable guess).

The values of the Young's modulus of the green compacted and sintered samples are low enough (18-20 GPa) compared to the values of the human bone, but nevertheless, the strength of the alloy is also low (260-310 MPa). If the porosity level of this alloy were higher (e.g., the introduction of macroporosity) the strength will be too low (expected strength 300-500 MPa) to use the material for load-bearing applications. The hot-pressed samples and samples produced by hot-pressing followed by sintering have roughly the same mechanical properties. Their Young's modulus values are too high, but the introduction of macroporosity would solve this problem. Nevertheless, the strength of these alloys is high enough and will allow the production of macroporous alloy with high strength. As the difference between the mechanical properties of hot-pressed and hot-pressed and sintered samples is not high, for further experiments we will use hot-pressing technique, as it is fast and simple. In order to check the strength value of a hot-pressed sample with high macroporosity, a space-holder method was applied. For our case, we are looking for such a space-holder material which will satisfy the following demands:

1. be safe and not toxic for the body

2. withstand high temperatures and pressures

3. can be easily removed from the metallic matrix.

$\mathrm{NaCl}$ satisfies all these demands, and was used to produce test samples with macroporosity of $45 \%$ by hot-pressing with space-holder. According to compression tests, the ultimate strength of these highly porous samples was in the range of $210 \pm 10 \mathrm{MPa}$, which is even higher than the strength of human cortical bone. The strength of the sample can be adjusted by the fraction of $\mathrm{NaCl}$ addition to the $\mathrm{Ti}-45 \mathrm{Nb}$ powder. One of the concerns of using $\mathrm{NaCl}$ as a space-holder is its relatively low melting point of $801^{\circ} \mathrm{C}$. If the molten space-holder material can chemically react with an alloy, it may dissolve the alloy and can wet the alloy powders, thus preventing their densification [19]. According to a study by Bansiddhi et al. [19], neither of this happens during the hot-pressing of TiNi alloy with $\mathrm{NaCl}$ space-holder at a temperature above $950{ }^{\circ} \mathrm{C}$. Besides that, the shape of the pores after $\mathrm{NaCl}$ dissolution stays rectangular, replicating the actual shape of $\mathrm{NaCl}$ solid crystals $[12,43,44]$. The results of our experiments agree with this. Another important concern in using $\mathrm{NaCl}$ as a space-holder is that it can increase the corrosion rate of the implant in the human body. To check this possibility, we carried out several additional tests. Figure 5 shows characteristic polarization curves that were 
measured on the cross-sectional areas of hot-pressed Ti-45Nb samples with microporosity in standard Ringer solution ( $\mathrm{pH}$ 7.5) and in solutions that were further modified by $\mathrm{NaCl}$ saturation and/or shift of $\mathrm{pH}$ value to $\mathrm{pH}$ 0.5. Notice that current density values are related to the geometrical electrode surface. In standard Ringer solution, the corrosion potential $\mathrm{E}_{\mathrm{corr}}$ establishes at about $-0.5 \mathrm{~V}$ vs. SCE, and is related to a corrosion current density value $i_{\text {corr }}$ of about $0.2 \mu \mathrm{A} / \mathrm{cm}^{2}$, which is indicative of a very low free corrosion reactivity of the alloy sample. Upon anodic polarization, a direct transfer into a passive plateau at a current density level of about $5 \mu \mathrm{A} / \mathrm{cm}^{2}$ occurs, which remains stable up to potential values $>1 \mathrm{~V}$ vs. SCE. In comparison, this polarization curve for a powder-metallurgically processed alloy sample is very similar to the one for a cast and solution-treated beta-phase Ti- $40 \mathrm{Nb}$ alloy sample (dashed line) measured under the same conditions. This alloy behavior is typical for the formation of barrier-type low conductive passive films on valve-metal species, and corresponds to a very high corrosion resistance of the material in the stability range of water-based solutions without any indication for chloride-induced pitting.

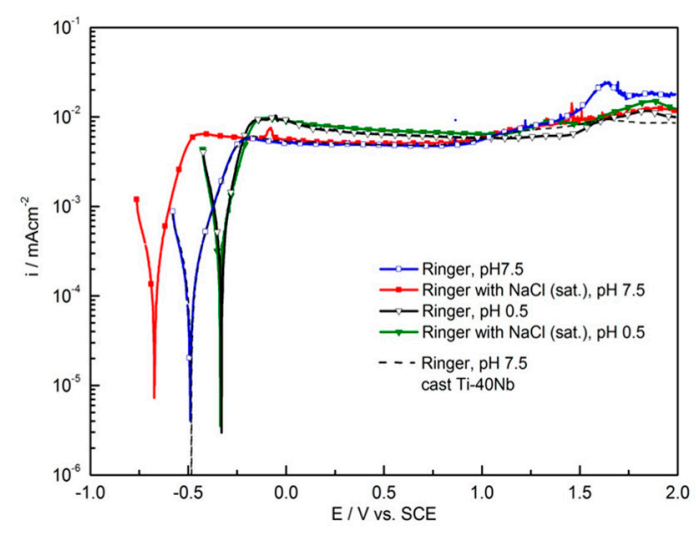

Figure 5. Characteristic potentiodynamic polarization curves of hot-pressed Ti-45Nb samples measured in Ringer solution with and without $\mathrm{NaCl}$ addition up to saturation and at different $\mathrm{pH}$ values and of reference cast $\mathrm{Ti}-40 \mathrm{Nb}$ sample at $\mathrm{pH} 7.5$.

When the Ringer solution is saturated with $\mathrm{NaCl}$, a negative shift of the corrosion potential $\mathrm{E}_{\text {corr }}$ by about $0.25 \mathrm{~V}$ vs. SCE and a slight steepening of the initial anodic slope are observed, which may be indicative of a certain activation of the alloy surface under free corrosion conditions. However, the corrosion current density remains low. An acidification of the Ringer solution from $\mathrm{pH} 7.5$ to $\mathrm{pH} 0.5$ (without and with $\mathrm{NaCl}$ saturation) has the consequence of a positive shift of the $\mathrm{E}_{\mathrm{corr}}$ value by about $0.17 \mathrm{~V}$ vs. SCE, together with a small increase of the $i_{\text {corr }}$ value to about $0.7 \mu \mathrm{A} / \mathrm{cm}^{2}$. These trends are mainly attributable to an increase of the hydrogen reduction rate in the acidic solutions. In all modified Ringer solutions, the anodic behavior of the hot pressed beta-phase Ti- $45 \mathrm{Nb}$ alloy reveals a very stable passivity similar to that observed in the standard solution. Altogether, it can be concluded that these hot pressed alloy samples exhibit a very high corrosion resistance, even under extreme solution conditions that may be relevant for an implantation situation. In summary, the $\mathrm{NaCl}$ particles act as a reliable space-holder material for processing gas atomized $\mathrm{Ti}-45 \mathrm{Nb}$ at hot-pressing conditions and even sintering above the melting temperature of $\mathrm{NaCl}$. The resultant samples have ultimate compression strength of $210 \pm 10 \mathrm{MPa}$, which is a high value for a macroporous material.

\section{Conclusions}

The following conclusions can be drawn from the present study:

1. Gas-atomized Ti-45Nb powders can be compacted by sintering at $1000{ }^{\circ} \mathrm{C}$ as well as hot-pressing at $600{ }^{\circ} \mathrm{C}$ and pressures of $25-50 \mathrm{kN}$, preserving the $\beta$-phase state. 
2. Sintering of green compacted powder yields samples with microporosities varying between $8 \%$ and $12 \%$. In compression, those samples showed low Young's modulus values in the range of 18-21 GPa, but low ultimate strengths of 261-308 MPa.

3. Hot pressing without or with subsequent sintering is effective for significant densification of the alloy powder compact, related to enhanced particle interconnection. Microporosities in the range of $1 \%-4 \%$ are achieved, and in compression the samples show a high Young's modulus in the range of 55-69 GPa, but also high strengths varying between 635 and $738 \mathrm{MPa}$. Hot-pressing of $\mathrm{Ti}-45 \mathrm{Nb}$ powder with $\mathrm{NaCl}$ space holder yields samples with macroporosity of $45 \%$, with a strength of more than $200 \mathrm{MPa}$, which is higher than the strength of a human cortical bone.

4. In addition, a very high chemical stability of compacted $\mathrm{Ti}-45 \mathrm{Nb}$ alloy samples was detected, even in extremely corrosive physiological environments.

Acknowledgments: The present work was supported by the DFG in the framework of the SFB-Transregio 79 project M1. Funding by the EU and the Free State Saxony (SAB grant No. 13853/2379) within the European Centre for Emerging Materials and Processes Dresden (ECEMP) is gratefully acknowledged.

Author Contributions: K.Z., I.O., M.C. and A.G. conceived and designed the experiments; K.Z. and I.O. performed the experiments; K.G.P., K.Z., M.C. and A.G. analyzed the data; K.G.P. and K.Z. wrote the paper. J.E. and A.G. supervised the research project.

Conflicts of Interest: The authors declare no conflict of interest.

\section{References}

1. Long, M.; Rack, H. Titanium alloys in total joint replacement-A materials science perspective. Biomaterials 1998, 19, 1621-1639. [CrossRef]

2. Burr, D.B.; Martin, R.B.; Schaffler, M.B.; Radin, E.L. Bone remodeling in response to in vivo fatigue microdamage. J. Biomech. 1985, 18, 189-200. [CrossRef]

3. Gong, J.K.; Arnold, J.S.; Cohn, S.H. Composition of trabecular and cortical bone. Anat. Rec. 1964, 149, 325-332. [CrossRef] [PubMed]

4. Nicholson, P.H.J.; Cheng, X.G.; Lowet, G.; Bonnen, S.; Davie, M.W.J.; Dequejer, J.; Van der Perre, G. Structural and material mechanical properties of human vertebral cancellous bone. Med. Eng. Phys. 1997, 19, 729-737. [CrossRef]

5. Kuroda, D.; Niinomi, M.; Morinaga, M. Design and mechanical properties of new $\beta$ type titanium alloys for implant materials. Mater. Sci. Eng. A 1998, 243, 244-249. [CrossRef]

6. Ho, W.F.; Ju, C.P.; Lin, J.H. Structure and properties of cast binary Ti-Mo alloys. Biomaterials 1999, 20, 2115-2122. [CrossRef]

7. Ozaki, T. Development of beta titanium alloys with low Young's modulus. In Proceedings of the Materials and Processes for Medical Devices Conference, Saint Paul, MN, USA, 25-27 August 2004; pp. 197-202.

8. Oh, I.H.; Nomura, N.; Masahashi, N.; Hanada, S. Mechanical properties of porous titanium compacts prepared by powder sintering. Scr. Mater. 2003, 49, 1197-1202. [CrossRef]

9. Zhuravleva, K.; Scudino, S.; Khoshkhoo, M.S.; Gebert, A.; Calin, M.; Schultz, L.; Eckert, J. Mechanical Alloying of $\beta$-Type Ti-Nb for Biomedical Applications. Adv. Eng. Mater. 2013, 15, 262-268. [CrossRef]

10. Zhuravleva, K.; Bönisch, M.; Scudino, S.; Calin, M.; Schultz, L.; Eckert, J.; Gebert, A. Phase transformations in ball-milled Ti-40Nb and Ti-45Nb powders upon quenching from the $\beta$-phase region. Powder Technol. 2014, 253, 166-171. [CrossRef]

11. Zhuravleva, K.; Bönisch, M.; Prashanth, K.G.; Hempel, U.; Helth, A.; Gemming, T.; Calin, M.; Scudino, S.; Schultz, L.; Eckert, J.; et al. Production of porous $\beta$-type Ti-40Nb alloy for biomedical applications: Comparison of selective laser melting and hot pressing. Materials 2013, 6, 5700-5712. [CrossRef]

12. Zhuravleva, K.; Chivu, A.; Teresiak, A.; Scudino, S.; Calin, M.; Schultz, L.; Eckert, J.; Gebert, A. Porous low modulus Ti40 $\mathrm{Nb}$ compacts with electrodeposited hydroxyapatite coating for biomedical applications. Mater. Sci. Eng. C 2013, 33, 2280-2287. [CrossRef] [PubMed]

13. Niu, W.; Bai, C.; Qiu, G.B.; Wang, Q. Processing and properties of porous titanium using space holder technique. Mater. Sci. Eng. A 2009, 506, 148-151. [CrossRef] 
14. Havaldar, R.; Pilli, S.C.; Putti, B.B. Insights into the effects of tensile and compressive loadings on human femur bone. Adv. Biomed. Res. 2014, 3, 101. [CrossRef] [PubMed]

15. Jha, N.; Mondal, D.P.; Majumdar, J.D. Highly porous open cell Ti-foam using $\mathrm{NaCl}$ as temporary space holder through powder metallurgy route. Mater. Des. 2013, 47, 810-819. [CrossRef]

16. Salimon, A.; Breehet, Y.; Ashby, M.F.; Greer, A.L. Potential applications of steel and titanium metal foams. J. Mater. Sci. 2005, 40, 5793-5799. [CrossRef]

17. Esen, Z.; Bor, S. Processing of titanium foams using magnesium spacer particles. Scr. Mater. 2007, 56, 341-344. [CrossRef]

18. Andrews, A.; Sanders, W.; Gidson, L.J. Compressive and tensile behavior of aluminum foams. Mater. Sci. Eng. A 1999, 270, 113-124. [CrossRef]

19. Bansiddhi, A.; Dudand, D.C. Shape-memory NiTi foams produced by replication of $\mathrm{NaCl}$ space-holders. Acta Biomater. 2008, 6, 1996-2007. [CrossRef] [PubMed]

20. Wen, C.E.; Mabuchi, M.; Yamada, Y.; Shimojima, K. Processing of biocompatible porous Ti and Mg. Scr. Mater. 2001, 45, 1147-1153. [CrossRef]

21. Jian, X.; Liao, Y.L.; Qiu, G.B. Titanium foams prepared by using carbamide as spaced for cortical bone implant. Mater. Sci. Forum 2015, 815, 321-326.

22. Michailidis, N.; Stergioudi, F.; Tsipas, D.N. Manufacturing of open-cell metal foams using a novel leachable pattern. Adv. Eng. Mater. 2011, 13, 29-32. [CrossRef]

23. Lee, M.H.; Kim, K.B.; Han, J.H.; Eckert, J.; Sordelet, D.J. High strength porous Ti-6Al-4V foams synthesized by solid state powder processing. J. Phys. D Appl. Phys. 2008, 41, 105404. [CrossRef]

24. Nakas, G.I.; Dericioglu, A.F.; Bor, S. Monotonic and cyclic compressive behavior of superelastic TiNi foams processed by sintering using magnesium space-holder technique. Mater. Sci. Eng. A 2013, 582, 140-146. [CrossRef]

25. Aydogmus, T.; Bor, E.T.; Bor, S. Phase transformation behavior of porous TiNi alloys produced by powder metallurgy using magnesium as a space holder. Metall. Mater. Trans. A 2011, 42, 2547-2555. [CrossRef]

26. Staiger, M.P.; Pietak, A.M.; Huadmai, J.; Dias, G. Magnesium and its alloys as orthopedic biomaterials: A review. Biomaterials 2006, 27, 1728-1734. [CrossRef] [PubMed]

27. Hornez, J.C.; Lefèvre, A.; Joly, D.; Hildebrand, H.F. Multiple parameter cytotoxicity index on dental alloys and pure metals. Biomol. Eng. 2002, 19, 103-117. [CrossRef]

28. Woodman, J.L.; Jacobs, J.J.; Galante, J.O.; Urban, R.M. Metal ion release from titanium-based prosthetic segmental replacements of long bones in baboons: A long-term study. J. Orthop. Res. 1984, 1, 421-430. [CrossRef] [PubMed]

29. Nouri, A.; Hodgson, P.D.; Wen, C. Study on the role of stearic acid and ethylene-bis-stearamide on the mechanical alloying of a biomedical titanium based alloy. Metall. Mater. Trans. A 2010, 41, 1409-1420. [CrossRef]

30. Major Hazards Assessment Panel. Ammonia Toxicity: A Report of the Major Hazards Assessment Panel Toxicity Working Party; IChemE: Rugby, UK, 1988.

31. Godley, R.; Starosvetsky, D.; Gotman, I. Corrosion behavior of a low modulus $\beta-\mathrm{Ti}-45 \% \mathrm{Nb}$ alloy for use in medical implants. J. Mater. Sci.: Mater. Med. 2006, 17, 63-67. [CrossRef] [PubMed]

32. Atkinson, H.V.; Davies, S. Fundamental aspects of hot isostatic pressing: An overview. Metall. Mater. Trans. A 2000, 31, 2981-3000. [CrossRef]

33. Sands, R.L.; Shakespeare, C.R. Powder Metallurgy Practice and Applications; Gerorge Newnes: London, UK, 1966; pp. 180-235.

34. Coble, R.L. Diffusion models for hot pressing with surface energy and pressure effects as driving forces. J. Appl. Phys. 1970, 41, 4798. [CrossRef]

35. Arzt, E.; Ashby, M.E.; Easterling, K.E. Practical applications of hot-lsostatic pressing diagrams: Four case studies. Metall. Mater. Trans. A 1983, 14, 211-221. [CrossRef]

36. De Fontaine, D.; Paton, N.E.; Williams, J.C. The omega phase transformation in titanium alloys as an example of displacement controlled reactions. Acta Mater. 1971, 19, 1153-1162. [CrossRef]

37. Illarionov, A.G.; Popov, A.A.; Grib, S.V.; Elkina, O.A. Special features of formation of omega-phase in titanium alloys due to hardening. Met. Sci. Heat Treat. 2011, 52, 493-498. [CrossRef]

38. Ikehata, H.; Nagasako, N.; Furuta, T.; Fukumoto, A.; Miwa, K.; Saito, T. First-principles calculations for development of low elastic modulus Ti alloys. Phys. Rev. B 2004, 70, 1741113. [CrossRef] 
39. Calin, M.; Helth, A.; Gutierrez Moreno, J.J.; Bönisch, M.; Brackmann, V.; Giebeler, L.; Gemming, T.; Lekka, C.E.; Gebert, A.; Schnettler, R.; et al. Elastic softening of $\beta$-type Ti-Nb alloys by indium (In) additions. J. Mech. Behav. Biomed. Mater. 2014, 39, 162-174. [CrossRef] [PubMed]

40. Todo, M.; Kuraoka, H.; Kim, J.; Taki, K.; Ohshima, M. Deformation behavior and mechanism of porous PLLA under compression. J. Mater. Sci. 2008, 43, 5644-5646. [CrossRef]

41. Budiansky, B. On the elastic moduli of some heterogeneous materials. J. Mech. Phys. Solids 1965, 13, $223-227$. [CrossRef]

42. Sun, J.; Yao, Q.; Xing, H.; Guo, W.Y. Elastic properties of $\beta, \alpha^{\prime \prime}$ and $\omega$ metastable phases in Ti-Nb alloy from first-principles. J. Phys. Condens. Matter 2007, 19, 486215-486223. [CrossRef]

43. Torres, Y.; Pavón, J.J.; Rodríguez, J.A. Processing and characterization of porous titanium for implants by using $\mathrm{NaCl}$ as space holder. J. Mater. Process. Technol. 2012, 212, 1061-1069. [CrossRef]

44. Wang, Q.Z.; Cui, C.X.; Liu, S.J.; Zhao, S.J. Open-celled porous Cu prepared by replication of $\mathrm{NaCl}$ space-holders. Mater. Sci. Eng. A 2010, 527, 1275-1278. [CrossRef]

(C) 2016 by the authors; licensee MDPI, Basel, Switzerland. This article is an open access article distributed under the terms and conditions of the Creative Commons Attribution (CC-BY) license (http://creativecommons.org/licenses/by/4.0/). 